\title{
THE NATURE OF CHRONIC AND TRANSIENT POVERTY: ANALYZING POVERTY DYNAMICS IN NEPAL
}

\author{
Prabin Khanal*
}

\begin{abstract}
Cross sectional data are widely applied for studying and analyzing poverty at a particular point in time. However, it does not incorporate the changes in welfare level of an individual over a period in time. This paper uses the concept of poverty dynamics for studying the chronic and transient nature of poverty in different areas of Nepal. Using the data of Nepal Living Standard Survey (NLSS) of 1995/96 and 2003/04, this study reveals that the concentration of chronic poverty is larger than the transient poverty. Policies required for taking out chronic and transient poor from the state of poverty should be applied in a different way.
\end{abstract}

JEL classification: I32

Keywords: Poverty dynamics, chronic poverty, transient poverty, panel data, Nepal

\section{INTRODUCTION}

The dynamic nature of poverty is crucial in analyzing changes in the welfare condition of people (Nguyen \& Popkin, 2003; Krishna, 2004; Ojha, 2007; Arrar et al., 2010). The use of cross sectional data is widely applied for analyzing static poverty which is based on different indicators, for example, income, and consumption among others. However, with some limitations, the study of the static nature of poverty cannot fully explain the changes in the welfare level of an individual over a period in time. The purpose of this paper is to analyze the dynamic nature of poverty in Nepal using the panel data sets for the year 1995/96 and 2003/04. ${ }^{1}$

The high population growth rate (annual growth rate is $1.40 \%$ ) and low economic growth (GDP growth rate is $3.97 \%$ in 2010) in comparison to neighboring countries are seriously hindering the poverty reduction initiative in Nepal (CBS, 2011). However, Nepal has reduced absolute poverty from 42\% in 1996 to 25\% in 2011 (CBS, 2011). Poverty headcount, subject to internal and external factors, considerably fell in 15 years between the periods of 1996 - 2011. One of the important factors associated

\footnotetext{
${ }^{*}$ Mr. Khanal is an independent researcher. Email: prabinkhanalecon@yahoo.com

${ }^{1}$ Central Bureau of Statistics (CBS) of Nepal collected the panel data set at 962 households two times in the year 1996 and 2004. This data set comprises the living standard of the people measured mainly in demographic situation, health condition, education facility, employment and consumption.
} 
with the reduction of poverty is remittances generated from migration (Lokshin et al., 2007). ${ }^{2}$ This has also resulted in an increased gross domestic consumption of country. Unfortunately investment in capital industry is not satisfactory. In 15 years period, there were changes in the education level, infant mortality rate, maternal mortality rate, life expectancy at birth and so forth which are considered to be basic indicators for human development (United Nations, 2012). ${ }^{3}$ The picture of poverty described above has to do with the existing rate of poverty and it does not explain out how many people fall into poverty, come out of the poverty, and the reasons for long term poverty. This kind of calculation of poverty at a particular point in time does not deal with the movement of people in and out of poverty.

Static analysis of consumption or income is common in welfare analysis. A large amount of literature can be found that deals with the static nature of welfare analysis (Fields and Ok, 1999). The static nature of welfare analysis studies the situation of a society at a particular point in time; however, the dynamic nature of welfare analysis provides the mobility of a person from one point in time to another (Bane \& Ellwood, 1986; Gaiha, 1988; Barrett et al., 2006; Barrett \& Carter, 2006; Bruck et al., 2010; Krishna \& Shariff, 2011). In particular, income or consumption mobility depends on distribution of income/consumption at different points in time. In order to analyze the distribution of welfare over time, and distinguish chronic from transient poverty, one needs to be able to follow the same households over time and to record their expenditure level (or other indicators of welfare) at different points in time.

This paper is organized as follows: After the introduction in the first section, second section reviews previous studies, third section deals with methodology and data. Section four discusses the results, and section five offers concluding remarks.

\section{LITERATURE REVIEW}

Determinants of chronic poverty are different from that of transient poverty (Jalan \& Ravallion, 2000). This fact is crucial in targeting the poverty reduction strategy. The study of poverty dynamics considers the situation of the same household or individual at different points of time. In order to analyze poverty dynamics, a longitudinal data set is required. Studies on poverty dynamics mainly focuses on two types of poverty, namely, chronic and transient poverty. Chronic poverty is defined as poverty for a long or extended period of time and transient poverty can be simply defined as poverty in short period of time (Hulme et al., 2001). The fundamental concern for categorizing chronic and transient poverty depends on the duration of time. There are different ways to distinguish long run and short run poverty (McKay \& Lawson, 2002). Welfare

2 For more details see (Lokshin et al., 2007). Lokshin et al. has found that one-fifth of poverty reduction that has been realized between 1996 and 2004 is associated with the labor migration particularly to foreign land. However, domestic migration also plays important role.

3 This report comprises the report covering all Millennium Development Goals. 
and development policies are important indicators that help distinguish chronic and transient poverty (Baulch \& Hoddinott, 2000). The transient nature of poverty could be reduced by adopting policies that help consumption or income smoothing, for example increased access to credit facilities. Chronic poverty is reduced with the help of transfer programs and these kinds of programs help the poor increase their level of income (Ravallion \& Chen, 2003). Chronic poverty affects the household welfare level in the long run and ultimately affects children's education and health and without proper policy intervention from the government, there is high risk of transferring poverty from one generation to the next (Isfahani \& Majbouri, 2010). According to Mckay and Lawson (2002)

"By their nature, the concepts of chronic and transient poverty relate to the dynamics of poverty. To make this distinction will require either: (i) longitudinal or panel data, where observations on the living conditions of the same individuals or household are made at several points in time, or (ii) information that captures dynamics aspects of living conditions even by just observing at point in time-such as retrospective or life histories, or one time indicators that have implications for duration, such as illiteracy or stunting."

Figure 1 describes the welfare movement of an individual household.

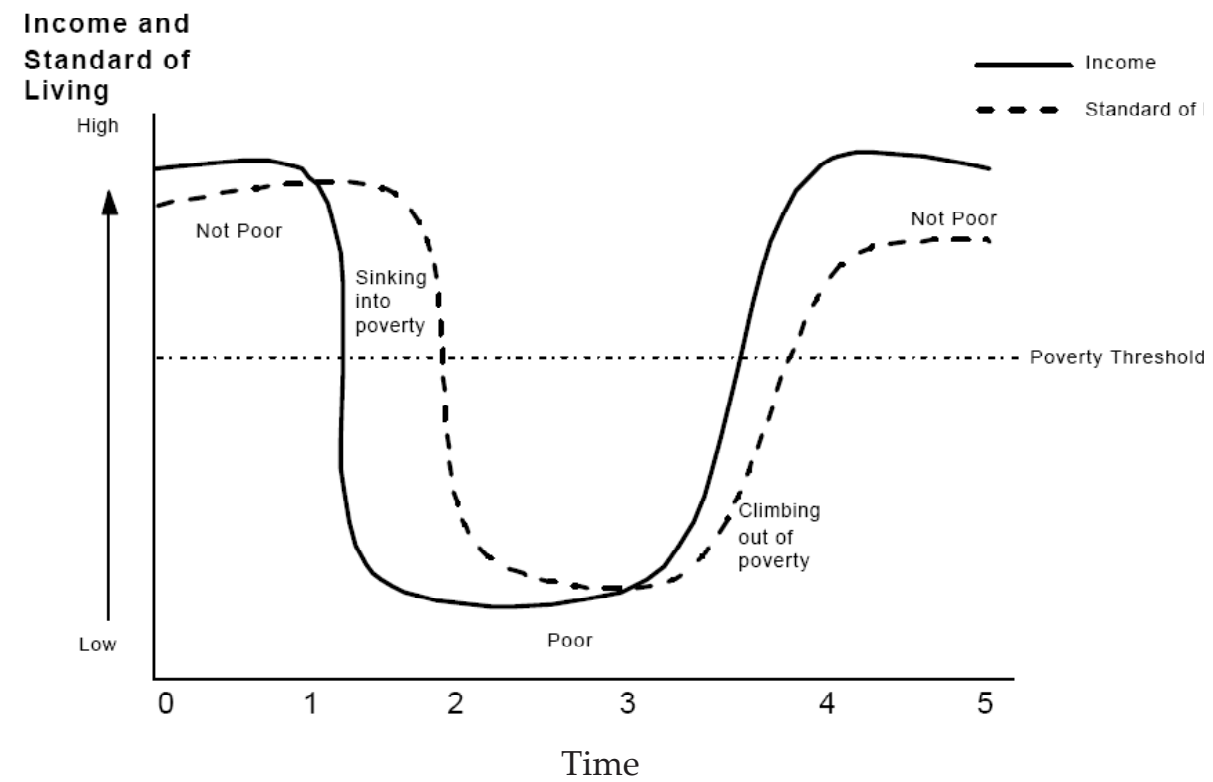

Source: Gordon (1989).

Figure 1: Dynamics of poverty 
The dotted line represents standard of living and the solid line is the income level of the household. Because of different circumstances (job gain or loss, increase or decrease of income, property loss due to natural disaster, illness for a long period of time etc) at different points in time, there is the movement of households from non-poor to poor state and vice versa.

According to Deininger and Okidi (2003), chronic poverty is related to the lack of human and physical capital, high dependency ratio, and remote location of disadvantaged community. A household suffers from transient poverty when there is no mechanism to solve the sudden changes in household or external conditions, for example, joblessness, natural disaster, inflation and so on. The nature and characteristics of transient poverty is different from that of chronic poverty (Jalan \& Ravallion, 1998, 2000; Gaiha \& Deolalikar, 1993).

Murdoch (1994) studies why households move in and out of poverty, and uses the concept of stochastic and structural poverty to describe this phenomenon. Households in developing countries are transient poor because they are unable to save themselves against stochastic event, for example joblessness, natural disaster and macroeconomic problems particularly inflation. According to Murdoch, a household suffers stochastic poverty when household current income falls below the poverty line and the permanent income is above the poverty line. A household suffers from structural or chronic poverty when current and permanent levels of income are always below the poverty line. Murdoch (1994) says that some factors like high dependency ratio and death of principal income earner may push a household into a chronic state of poverty. Carter and May (1999) also supports the idea of Murdoch (1994). According to Jalan and Ravallion (2000):

"Some of the poverty observed at one date arises from a low long-term level of living; call this 'chronic poverty'. However, some of any currently observed poverty is likely to be a temporary state due to, say, a negative income shock; call this 'transient poverty'. This type of poverty stems from the vulnerability of people to a drop in their living standards; non-poor people at normal times might suddenly fall into poverty, or people living not much below the poverty line might suddenly fall into extreme poverty ( $p .1) . "$

Research on poverty has been carried out for long time. The focus of poverty analysis is based on a particular point in time. Clearly, such studies have not been able to deal with the movement of households into and out of poverty. So, poverty should be analyzed by its dynamic nature and following this philosophy many researchers have conducted studies on poverty dynamics since early 1980s. The availability of panel data on household living standards since early 1980s made the research more comprehensive. 
Different studies on household panel data are conducted for analyzing the movement of household into and out of poverty and for this different measure of poverty are taken into the consideration. Some employ fixed variable measure such as asset index and some employ flow variables such as income or consumption expenditures. Carter and May (2001), Adato et. al (2006) and Mogues (2006) employed asset index to analyze the dynamic nature of poverty. However, Jalan and Ravallion (2000) used flow variables such as income or consumption expenditures to analyze the dynamic nature of poverty. To examine the poverty dynamics in different settings many researchers have used panel data analysis. However, some provided the results of cross sectional analysis to justify the result.

Poverty analysis has been a key issue for a long time and the analysis is based on several existing situations across different nations. Its analysis has changed depending upon the availability of information. Poverty research has many aspects, for example, poverty at a point, poverty dynamics, and multidimensional nature of poverty, asset poverty, and so forth. All of them have different approaches but the ultimate goal of any research on poverty is to provide recommendations to reduce poverty in any form. Dynamic analysis of poverty must cover at least two periods of time for the same household or person. In connection to this, several researchers have carried out research on the dynamic nature of poverty in different settings. Nelson and Tasie in 2011 demonstrated in Ethiopia that asset index is a more powerful tool to analyze poverty dynamics than flow variables such as consumption expenditure and income. They used the panel data from Ethiopia and generated the asset based and expenditure based poverty. Their findings suggest that asset dynamics should be considered to analyze poverty and should be employed as a tool to target poverty. However, there is fundamental question as to how to calculate the value of assets within households. In case of developed countries, these asset indices cannot be employed to analyze the dynamic nature of poverty because irrespective of the income level basic assets like education and public facilities are the same. The theoretical background on the asset poverty dynamics can be found in Carter and May (2001), Adato et. al (2006) and Mogues (2006) among others.

\section{METHODOLOGY AND DATA}

Existing literature provides two commonly applied approaches to analyze chronic and transient poverty:

\section{Approach I}

This approach examines the duration of poverty and recognizes a chronically poor household. If per capita income or consumption of any household is below the poverty line at all observation points, then the household is referred to a chronically poor household. However, household in transient poverty depicts the fluctuation in income or consumption around the poverty line (Baulch \& Hoddinott 2000; Baulch \& Masset 2003). 


\section{Approach II}

This approach follows the permanent income hypothesis and explains that income and consumption have fixed and varying components and empirical differences between these two components can be shown (Jalan \& Ravallion, 2000). According to this approach, a household is said to be chronically poor if its income is always at or below fixed (permanent) income.

This paper uses the component approach method developed by Ravallion and Jalan $(1998,2000)$ to analyze the chronic and transient poverty in Nepal using data from the NLSS. Jalan and Ravallion (2000) decomposed the poverty at household level into two components: chronic and transient in rural China. When a household mean level of consumption expenditure or income is below the poverty line, then the household suffers from chronic poverty. And transient poverty is the result of difference between total poverty and chronic poverty.

"Transient poverty" is the component of time-mean consumption poverty at household level that is directly attributable to variability in consumption; this can be thought of as a measure of vulnerability to falling consumption. The non-transient component then depends solely on mean consumption over time, and we call this 'chronic poverty" (Jalan and Ravallion, 2000.p.1)

The definition of an aggregate inter-temporal poverty measure given by Jalan and Ravallion (2000) for the ith household is represented as:

$$
P_{i}=P\left(y_{i 1}, y_{i 2}, \ldots, y_{i T}\right)
$$

where i represents the household and $1,2, \ldots, \mathrm{T}$ represent different points of time; $\mathrm{y}$ is the welfare level of household expressed either in consumption or income; P represents welfare measure or poverty measure. Jalan and Ravallion (2000) (here after J-R) used the Foster- Greer -Thorbecke (hence forth FGT) (1984) measure to compute poverty at household level. Total poverty is defined as the inter-temporal mean of the poverty measures at different period of time.

$$
\mathrm{P}=\frac{1}{\mathrm{~T}} \sum_{\mathrm{t}=1}^{\mathrm{T}} \mathrm{P}_{\mathrm{it}}
$$

where T is the total number of years. J-R (2000) use the FGT (1984) measure of total poverty that is squared poverty gap index for the analysis.

$$
P_{\text {it }}=\left\{\frac{\left(z-y_{\text {it }}\right)^{\alpha}}{z}, y_{\text {it }}<\mathrm{z} ; y_{\text {it }} \geq \mathrm{z} ; 0\right.
$$


where $\mathrm{z}$ is the poverty line.

J-R's chronic poverty is represented by the expression:

$$
\mathrm{P}_{\alpha}=\frac{1}{\mathrm{~N}} \sum_{\mathrm{i}=1}^{\mathrm{n}} \frac{\left(\mathrm{z}-\overline{\mathrm{y}_{\mathrm{i}}}\right)^{\alpha}}{\mathrm{z}}
$$

where $\overline{\mathrm{yi}}$ is the average consumption expenditure of ith household ; $\mathrm{N}$ is total number of households; $P_{\alpha}$ is the J-R chronic poverty; $\mathrm{n}$ is the number of households below the poverty line ; $\mathrm{z}$ is the poverty line.

Then transient poverty is defined as TRP $=$ TOP-CHP

where TRP $=$ Transient Poverty; TOP= Total Poverty; $\mathrm{CHP}=$ Chronic Poverty

J-R approach calculates the chronic and transient poverty using the squared poverty gap index. However, the purpose of this paper is to use all forms of FGT indexes for the calculation of chronic and transient poverty in Nepal and analyze the poverty situation in urban, rural and entire Nepal.

The panel data for the analysis of poverty in this paper come from NLSS reports 1995/96 and 2003/04 published by the Central Bureau of Statistics (CBS) of the government of Nepal. The NLSS panel data set comprises different socio-economic and household characteristics. This is the most comprehensive and well designed household level survey in Nepal conducted by the government. The social and economic indicators covered in the NLSS reports the factors that directly affect the livelihood of Nepalese people. The number of households used as panel households is 962 .

\section{RESULT AND DISCUSSION}

Firstly, the J-R approach is used to calculate the total, chronic and transient poverty in Nepal. Secondly, the same approach is used to estimate the total, chronic and transient poverty in rural and urban areas. Clearly the total poverty in rural areas is higher than that in urban areas but the concentration of poverty in different parts of rural areas is different. In order to capture all those differences, rural area of Nepal is further studied into Eastern and Western, and again Eastern and Western regions are segregated into hill and Terai regions. For the estimation of JR chronic and transient poverty, one should first measure the total poverty. The poverty line is based on the poverty line estimated by the Nepal Central Bureau of Statistics. Table 1 shows the poverty lines at two points, in 1996 and 2004. 
Table 1: Poverty Lines in Different Regions

\begin{tabular}{lcc}
\hline Regions & $1995 / 96$ & $2003 / 04$ \\
\hline Kathmandu & 6,676 & 16,364 \\
Other Urban & 5,452 & 11,694 \\
Rural Western Hill & 5,403 & 13,174 \\
Rural Eastern Hill & 5,734 & 11,943 \\
Rural Western Terai & 4,173 & 10,979 \\
Rural Eastern Terai & 4,655 & 8,997 \\
All Nepal & 5,089 & 11,390 \\
\hline
\end{tabular}

Source: CBS, 2005

The poverty line is estimated by totalling the expenditure on food and non-food items. On top of it, the definition given by Jalan and Ravallion $(1998,2000)$ is used to calculate total, chronic and transient poverty. The J-R approach uses the Foster-Greer-Thorbecke (FGT) measure of poverty to analyze the chronic and transient nature of poverty. This approach uses squared poverty gap index to estimate out the total poverty into chronic and transient poverty. However, this study undertakes all forms of poverty measure, head count poverty index (poverty incidence), poverty gap and squared poverty gap to segregate total poverty into chronic and transient poverty. This analysis compares all chronic and transient poverty in different regions and areas of Nepal. The degree of total poverty is different in all regions of Nepal. But, clearly the poverty situation in urban area is lower than in other parts of the country.

In order to categorize households into poor and non poor, the poverty line calculated by the CBS for various regions is used. The poverty line for different regions clearly shows that the poverty line set for the urban area is much higher than for other parts of the country. In urban areas the poverty line set in 1996 is Nepalese Rupees (NRs) 5,452 and in 2004 it is NRs 11,694. The poverty line in the rural area of Eastern Terai is NRs 4,655 and NRs 8,997 respectively which is the lowest among the poverty lines in other regions in Nepal. The average poverty line in the rural part of Eastern Terai is even lower than that of average poverty line of Nepal. Kathmandu has the highest poverty line of NRs 6676 and NRs 16364 in 1996 and 2004 respectively. The poverty line is calculated on the basis of cost of basic needs approach which calculates food poverty and non food poverty line. Calculating all food and non food expenditures in different regions of Nepal, poverty lines for different regions are estimated. ${ }^{4}$

4 The poverty line estimated by CBS uses the concept of Cost of Basic Needs (CBS) approach. The approach combines the food and non food expenditure and designs the poverty line. In Nepal, the average calorie intake per person per day in 1996 is $2124 \mathrm{kcal}$ and on the basis of different spatial prices of 37 food items in one basket, the food poverty line is estimated. Adding the food and non-food expenditure, poverty line is estimated. For more details of this approach, see Poverty Trends in Nepal (1995-96 and 2003-04) by CBS (2005). 
Table 2 through 8 highlight the breakdown of total poverty into chronic and transient poverty using the concept of Jalan and Ravallion (2000) approach. The poverty incidence, poverty gap and squared poverty gap are the three different poverty measurements used to find the chronic and transient poverty in Nepal and different rural and urban regions. In order to check the sensitivity of the result, the poverty incidence index and poverty gap index are added to see the difference in the calculations carried out by taking squared poverty gap index.

Table 2: Nepal Chronic and Transient Poverty

\begin{tabular}{lccc}
\hline \multicolumn{1}{c}{ Index } & Total poverty & Chronic Poverty & Transient Poverty \\
\hline Poverty Incidence $(\alpha=0)$ & 0.339 & $0.298(88 \%)$ & $0.041(12 \%)$ \\
Poverty Gap $(\alpha=1)$ & 0.096 & $0.067(70 \%)$ & $0.028(30 \%)$ \\
Squared Poverty Gap $(\alpha=2)$ & 0.038 & $0.023(60 \%)$ & $0.015(40 \%)$ \\
\hline
\end{tabular}

Table 3: Rural Chronic and Transient Poverty

\begin{tabular}{lccc}
\hline \multicolumn{1}{c}{ Index } & Total poverty & Chronic Poverty & Transient Poverty \\
\hline Poverty Incidence $(\alpha=0)$ & 0.379 & $0.333(89 \%)$ & $0.046(11 \%)$ \\
Poverty Gap $(\alpha=1)$ & 0.105 & $0.072(69 \%)$ & $0.033(31 \%)$ \\
Squared Poverty Gap $(2)$ & 0.041 & $0.023(56 \%)$ & $0.018(44 \%)$ \\
\hline
\end{tabular}

Table 4 : Urban Chronic and Transient Poverty

\begin{tabular}{lccc}
\hline \multicolumn{1}{c}{ Index } & Total Poverty & Chronic Poverty & Transient Poverty \\
\hline Poverty Incidence $(\alpha=0)$ & 0.174 & $0.135(78 \%)$ & $0.038(22 \%)$ \\
Poverty Gap $(\alpha=1)$ & 0.054 & $0.044(81 \%)$ & $0.010(19 \%)$ \\
Squared Poverty Gap $(\alpha=2)$ & 0.024 & $0.020(83 \%)$ & $0.003(17 \%)$ \\
\hline
\end{tabular}

Table 5: Rural Eastern Terai Chronic and Transient Poverty

\begin{tabular}{lccc}
\hline \multicolumn{1}{c}{ Index } & Total Poverty & Chronic Poverty & Transient Poverty \\
\hline Poverty Incidence $(\alpha=0)$ & 0.337 & $0.293(87 \%)$ & $0.045(13 \%)$ \\
Poverty Gap $(\alpha=1)$ & 0.089 & $0.066(74 \%)$ & $0.023(26 \%)$ \\
Squared Poverty Gap $(\alpha=2)$ & 0.034 & $0.022(65 \%)$ & $0.012(35 \%)$ \\
\hline
\end{tabular}

Table 6: Rural Eastern Hill Chronic and Transient Poverty

\begin{tabular}{lccc}
\hline \multicolumn{1}{c}{ Index } & Total Poverty & Chronic Poverty & Transient Poverty \\
\hline Poverty Incidence $(\alpha=0)$ & 0.305 & $0.263(86 \%)$ & $0.042(14 \%)$ \\
Poverty Gap $(\alpha=1)$ & 0.079 & $0.048(61 \%)$ & $0.031(39 \%)$ \\
Squared Poverty Gap $(\alpha=2)$ & 0.030 & $0.014(47 \%)$ & $0.016(53 \%)$ \\
\hline
\end{tabular}


Table 7: Rural Western Hill Chronic and Transient Poverty

\begin{tabular}{lccc}
\hline & Total Poverty & Chronic Poverty & Transient Poverty \\
\hline Poverty Incidence $(\alpha=0)$ & 0.423 & $0.387(91 \%)$ & $0.036(9 \%)$ \\
Poverty Gap $(\alpha=1)$ & 0.124 & $0.078(63 \%)$ & $0.046(37 \%)$ \\
Squared Poverty Gap $(\alpha=2)$ & 0.049 & $0.022(45 \%)$ & $0.027(55 \%)$ \\
\hline
\end{tabular}

Table 8: Rural Western Terai Chronic and Transient Poverty

\begin{tabular}{lccc}
\hline & Total Poverty & Chronic Poverty & Transient Poverty \\
\hline Poverty Incidence $(\alpha=0)$ & 0.459 & $0.423(92 \%)$ & $0.036(8 \%)$ \\
Poverty Gap $(\alpha=1)$ & 0.112 & $0.084(75 \%)$ & $0.029(25 \%)$ \\
Squared Poverty Gap $(\alpha=2)$ & 0.039 & $0.025(64 \%)$ & $0.014(36 \%)$ \\
\hline
\end{tabular}

Source: Tables 2 -8: Author's calculation from data of NLSS of 1995/96 and 2003/04.

The total poverty measure estimated using poverty incidence, poverty gap and square poverty gap index are 34\%, 9.6\% and 3.8\% respectively in Nepal. The total poverty in rural areas is $38 \%$ for poverty incidence where as when using poverty gap and squared poverty measure the total poverty is $10.5 \%$ and $4.1 \%$ respectively. The respective total poverty measures in urban areas are clearly low, $17.4 \%, 5.4 \%$ and $2.4 \%$. Among all regions, the types of poverty in Rural Western Terai is serious as all total poverty measures are exceedingly high, that is, $46 \%, 11.2 \%$ and $3.9 \%$ respectively.

When poverty incidence is taken into consideration, chronic poverty accounts for $88 \%, 89 \%$ and $78 \%$ respectively in Nepal, rural and urban areas. The transient poverty accounts for $12 \%, 11 \%$ and $22 \%$ respectively in Nepal, rural and urban areas. This suggests that chronic poverty is very high everywhere in the country. The dominance of chronic poverty on total poverty is high and it is subject to many factors such as high unemployment, low percentage of skilled man power in workforce, high dependency ratio and large number of people engaged in agriculture. In different Western and Eastern rural areas, the dominance of chronic poverty on total poverty is seriously high.

When using both the poverty gap and squared poverty gap index, the dominance of chronic poverty on total poverty is less than when using the poverty incidence measure to calculate total poverty. This analysis shows that when taking poverty gap to measure total poverty, the dominance of chronic poverty is the highest in urban areas at $(81 \%)$ as shown in table 5 and lowest in Rural Eastern Hill (61\%) as shown in table 6. This shows the poverty gap is the higher in urban areas than rural areas. Tables 2 to 8 show that irrespective of the poverty measures we use, the concentration of chronic poverty on total poverty is much higher than that of transient poverty. 


\section{CONCLUSION}

This study analyzes the chronic and transient poverty in different areas of Nepal using the NLSS data of 1995/96 and 2003/04 by applying the Jalan and Ravallion approach. Based on different poverty measurement, percentages of chronic and transient poor are calculated. When different measures of poverty are used to calculate, the dominance of chronic poverty over transient is found to be larger in almost all regions in Nepal. Policies needed to take out chronic and transient poor from the state of poverty should be different and the treatment should be applied differently. Policies adopted by the government are very important in reducing the chronic and transient poverty. Long term poverty reduction programs should be launched in order to reduce chronic poverty. It could be comprehensive programs that targets poor and cover important issues for example, employment generation, vocational education, infrastructure and health and sanitation development programs.

\section{References}

Adato, M., Carter, M. R., \& May, J. (2006). Exploring poverty traps and social exclusion in South Africa using qualitative and quantitative data. Journal of Development Studies, 42(2), 226-247.

Araar, A., Duclos, J. \& Giles, J. (2010). Chronic and transient poverty: Measurement and estimation, with evidence from China. Journal of Development Economics, 91, 266-277.

Bane, M., \& Ellwood, D. (1986). Slipping into and out of poverty: The dynamics of spells. Journal of Human Resources, 21(1), 1-23.

Barrett, C., \& Carter, M. (2006). The economics of poverty traps and persistent poverty: An asset-based approach. The Journal of Development Studies, 42(2), 178-199.

Barrett, C. B., Marenya, P. P., Mcpeak, J., Minten, B., Murithi, F., Kosura, W.O., Place, F., Randrianarisoa, J. C., Rasambainarivo, J., \& Wangila, J. (2006). Welfare dynamics in rural Kenya and Madagascar. Journal of Development Studies, 42 (2), 248-277.

Baulch, R., \& Hoddinott, J. (2000). Economic mobility and poverty dynamics in developing countries. Journal of Development Studies, 36(6), 1-24.

Baulch, B., \& Masset, E. (2003). Do monetary and non monetary indicators tell the same story about chronic poverty? A study of Vietnam in the 1990s. World Development, 31, 441-445.

Bruck, T., Danze, A.M., Muravyev, A. \& Weisshaar, N. (2010). Poverty during transition: Household survey evidence from Ukraine. Journal of Comparative Economics, $38,120-145$. 
Carter, M. R., \& May, J. (2001). One kind of freedom: poverty dynamics in postapartheid South $\quad$ Africa. World Development, 29(1), 1987-2006.

Central Bureau of Statistics (CBS, 2005). Poverty trends in Nepal (1995-96 and 2003-04). Kathmandu: Author

Central Bureau of Statistics (CBS, 1996).Nepal living standard survey 1995/96. Kathmandu: Author

Central Bureau of Statistics (CBS, 2004). Nepal living standard survey 2003/04. Kathamndu: Author

Central Bureau of Statistics (CBS, 2011). Nepal Living Standards Survey 2010/11. Central Bureau of Statistics. Kathmandu:Author

Central Bureau of Statistics (CBS, 2011). Nepal in Figure. Kathmandu: Author

Deininger, K., \& Okidi, J. (2003). Growth and Poverty Reduction in Uganda, 1999-2000: Panel Data Evidence. Development Policy Review, 21, 481-509.

Fields, G. \& Ok, E. (1999). Measuring movement of incomes. Economica, 66, 445-471.

Foster, J., Greer, J. \& Thorbecke, E. (1984). A class of decomposable poverty measures. Econometrica, 52, 761-776.

Gaiha, R. \& Deolalikar, A. (1993). Persistent, Expected and Innate Poverty: Estimates from Semi Arid Rural India, 1974-1984. Cambridge Journal of Economics, 17(4), 409-421.

Gaiha, R. (1988). Income mobility in rural India. Economic Development and Cultural Change, 36 (2), 279-302.

Gordon, D. (1989). Definitions of concepts for the perceptions of poverty and social exclusion. Retrieved March 12, 2012 from http://www.bris.ac.uk/poverty/ pse/99-Pilot/99-Pilot_1.pdf.

Hulme, D., Karen, M. \& Andrew, S. (2001). Chronic poverty: Meanings and analytical frameworks. CPRC Working Paper 2, IDPM, University of Manchester.

Isfahani, D. S. \& Majbouri, M. (2010). Mobility and the dynamics of poverty in Iran: Evidence from the 1992-1995 panel survey. The Quarterly Review of Economics and Finance.

Jalan, J. \& Ravallion, M. (1998). Transient poverty in post-reform rural China. Journal of Comparative Economics, 26, 338-357.

Jalan, J. \& Ravallion, M. (1998). Are the poor less well insured? Evidence on vulnerability to income risk in rural China. Journal of Development Economics, 58, 61-82.

Jalan, J. \& Ravallion, M. (2000). Is transient poverty different? Evidence for rural China. The Journal of Development Studies, 36(6), 82-99. 
Krishna, A. (2004). Escaping poverty and becoming poor: Who gains, who losses, and why? World Development, 32(1), 121-136.

Krishna, A. \& Shariff, A. (2011). The irrelevance of national strategies? Rural poverty dynamics in states and regions of India, 1993-2005. World Development, 39(4), 533-549.

Lokshin, M., Osmolovski, M.B., \& Glinskaya, E. (2007). Poverty reduction in Nepal. World Bank Policy Research Working Paper 4231.Washington, D.C.: The World Bank,

McKay, A., \& Lawson, D. (2002). Chronic Poverty: A review of current quantitative evidence. Chronic Poverty Research Center Working Paper No. 15, School of Economics, University of Nottingham.

Mogues, T. (2006). Shocks, livestock asset dynamics and social capital in Ethiopia. DSGD Discussion Paper No. 38. Washington, DC. International Food Policy Research Institute (IFPRI),

Murdoch, J. (1994). Poverty and vulnerability. American Economic Review, 84, 221-225.

Nelson, A. W. \& Tasie, L. S. O. L. (2011). Asset versus consumption poverty and poverty dynamics in rural Ethiopia. Agricultural Economics, 42, 221-233.

Nguyen, M.T. \& Popkin, B. M. (2003). Income and health dynamics in Vietnam: Poverty reduction, increased health inequality. Population, 58, 2253-2254.

Ohja, R.K. (2007). Poverty dynamics in rural Uttar Pradesh. Economic and Political Weekly, 42, 1453-1458.

Ravallion, M. (1988). Expected poverty under risk-induced welfare variability. Economic Journal, 98, 1171-1182.

Ravallion, M. \& Chen, S. (2003). Measuring pro-poor growth. Economic Letters, 78, 9399.

Sen, B. (2003). Drivers of escape and descent: Changing household fortunes in rural Bangladesh. World Development, 31, 513-534.

United Nations (2012). The millennium development goals report 2012.New York: Author 